\title{
Coastal and Marine Quality and Tourists' Stated Intention to Return to Barbados
}

\author{
Peter Schuhmann ${ }^{1,}$, Ryan Skeete ${ }^{2}$, Richard Waite ${ }^{3}$, Prosper Bangwayo-Skeete ${ }^{4}$, James Casey ${ }^{5}$, \\ Hazel A. Oxenford ${ }^{6}$ and David A. Gill ${ }^{7}$ \\ 1 Department of Economics and Finance, University of North Carolina Wilmington, \\ Wilmington, NC 28403, USA \\ 2 Caribbean Tourism Organization, Warrens, St. Michael BB22026, Barbados; skeeteryan@gmail.com \\ 3 World Resources Institute, Washington, DC 20002, USA; RWaite@wri.org \\ 4 Department of Economics, The University of the West Indies, Cave Hill BB11000, Barbados; \\ prosper.bangwayo-skeete@cavehill.uwi.edu \\ 5 Williams School of Commerce, Economics and Politics, Washington and Lee University, \\ Lexington, VA 24450, USA; caseyj@wlu.edu \\ 6 Centre for Resource Management and Environmental Studies, University of the West Indies, \\ Cave Hill BB11000, Barbados; oxenford.hazel@gmail.com \\ 7 Nicholas School of the Environment, Duke University Marine Lab, Beaufort, NC 28516, USA; \\ david.gill@duke.edu \\ * Correspondence: schuhmannp@uncw.edu; Tel.: 1-910-962-3417
}

Received: 2 May 2019; Accepted: 13 June 2019; Published: 17 June 2019

\begin{abstract}
Seawater quality is critical for island and coastal communities dependent on coastal tourism. Improper management of coastal development and inland watersheds can decrease seawater quality and adversely impact marine life, human health, and economic growth. Agricultural runoff and improper sewage management compromise nearshore water quality in many coastal regions and can impact visitation decisions of tourists who are drawn to these destinations. The purpose of this paper is to understand how tourists' decisions to revisit Barbados might be affected by changes in coastal and marine quality. We use data collected from tourists to examine how tourists' stated willingness to return is affected by scenarios involving changes in seawater quality, beach width and coral reef health. Results reveal that return decisions are sensitive to changes in all aspects of coastal and marine quality. A reduction in seawater quality discourages tourists' intention to return more than other environmental factors. These results are of paramount interest to destination managers, marketers and policymakers who rely on repeat visitation data to develop marketing strategies and infer future direction. This research highlights the importance of prioritizing seawater quality management to protect the coastal tourism product, especially in small island developing states (SIDS) with a high reliance on tourism income.
\end{abstract}

Keywords: seawater quality; contingent behavior; tourism; Barbados

\section{Introduction}

Clean beaches, clear turquoise waters and healthy coral reefs provide the principal settings for tourism activity in the Caribbean [1,2]. Coastal development is needed to support this tourism, but when improperly managed can have negative impacts on the natural assets that attract visitors. For example, losses in coral reef quality can have an array of impacts due to their prominent role in creating and protecting beaches, protecting coastal infrastructure, and providing aesthetic value for divers and snorkelers. 
Management of coastal runoff and sewage is especially important for areas that depend on coastal tourism, as seawater quality is directly connected to human and ecosystem health. Approximately 30 percent of the Caribbean's coral reefs are at high risk from threats like runoff, sedimentation and the discharge of untreated domestic and hotel wastewater [3,4]. When nutrient-rich effluents found in agricultural runoff and sewage are deposited into natural water courses [5], microalgae (phytoplankton) [6] and macroalgae (seaweed) grow rapidly and out-compete coral for space on the reef [7]. Suspended sediment also blocks light [6], and when it settles it smothers the reef, destroying living spaces, damaging corals and other benthic fauna and preventing settlement of new coral recruits [8]. Contaminated seawater can also lead to a variety of human health hazards through ingestion or contact with pathogenic microorganisms, including gastroenteric illnesses such as diarrhea, or infections of the upper respiratory tract, ears, eyes, nasal cavity and skin [9]. Real or perceived risks involving the quality of recreational seawater therefore have important economic implications in areas that depend on tourism as a primary source of income [10].

A significant and growing literature attempts to understand the tradeoffs between coastal and marine quality and the economic returns from tourism. Much of this literature uses revealed and stated preference valuation methods to estimate willingness to pay (WTP) for "non-market" aspects of coastal and marine quality such as beach width, coral reef health and biodiversity. WTP estimates can be informative for policy and management decisions. For example, estimates of WTP can be used to understand the economic benefits of improving or maintaining resource quality to inform cost-benefit analyses. WTP estimates can also be used to identify potential sources of funding for conservation and management, to design incentives that promote sustainable behavior, and to highlight the opportunity costs of resource degradation.

Because the assumptions necessary to employ revealed preference methods do not apply to many non-market environmental goods [11], and actual (behavioral) data can be costly to obtain, especially for goods that are purchased infrequently [12], stated preference methods such as the contingent valuation method (CVM) and choice experiments (CE) are often employed in WTP investigations. Stated preference methods provide the advantage of allowing for the examination of scenarios involving hypothetical changes that are outside the range of historical conditions [13] and can be used to estimate non-use values.

Recent examples include Halkos and Matsiori [14], who use CVM to estimate residents' WTP for a state-managed program of coastal zone improvements in Volos, Greece. Their results suggest that a substantial proportion of respondents are willing to pay for improving coastal zone quality, and that improving the quality of bathing water is the most important reason for WTP. García-Ayllón [15] present a novel approach to CVM, combining WTP estimates with participatory GIS mapping and process optimization to formulate environmental management solutions on the Spanish Mediterranean coast. Recent applications of CVM in the Caribbean include Casey and Schuhmann [16] and Schuhmann et al. [17], who measure tourists' willingness to pay conservation fees in Belize and Barbados respectively, and Trujillo et al. [18], who use the contingent valuation method (CVM) to estimate recreational divers' willingness to pay for the conservation of the coral reefs in the Columbian Caribbean.

Applications of the CE method include Pakalniete et al. [19], who estimate Latvian citizens' WTP for improving seawater quality for recreation, avoiding reductions in marine biodiversity and limiting new occurrences of invasive alien species in coastal and marine waters of the Baltic Sea. Of these attributes, they find that WTP is highest for better seawater quality. Christie et al. [20] estimate the benefits from six attributes associated with marine protected areas (MPAs) in St. Vincent and the Grenadines (SVG): Fishing quality, coastal protection, water quality (as related to human health), species diversity, beach recreation and diving/snorkeling recreation. The authors find that both locals and tourists on the South coast of St. Vincent were willing to pay the most for avoiding declines in human health related to water quality, followed by improvements to human health. Numerous other WTP studies estimate the monetary value that Caribbean beachgoers and underwater recreationists 
attribute to clean and wide beaches, healthy reefs, diverse fish populations and encounters with species such as sea turtles [21-23], with similar results found outside the region [24-26].

While monetary estimates of WTP for changes in resource quality are valuable for many reasons, policy makers in tourism-dependent areas can also benefit from an appreciation for how people's behavior will change in response to changes in resource quality. For example, an understanding of how tourists' willingness to return to a destination is related to the quality of the natural environment can help policy makers plan for changes in demand, anticipate changes in visitor profiles or plan targeted interventions to influence the behavior of demographic groups [27]. In tourism-dependent destinations where arrivals and return visitation are important measures of success, understanding how willingness to return depends on environmental quality might be a more tangible and relevant measure of socioeconomic outcomes than WTP. Furthermore, this "contingent behavior" approach may minimize some of the difficulties associated with traditional WTP estimation, such as respondents' unfamiliarity with formulating monetary estimates of WTP, and moral objection to monetizing nature. While methodologically similar to CVM, applications of the contingent behavior approach are relatively rare in the literature, especially as related to Caribbean tourism.

The purpose of this study is to complement and add to the existing valuation literature by assessing the potential effect of changes in seawater quality, beach width and coral reef health on visitors' stated intention to return to Barbados. This inquiry is novel, as we estimate Caribbean tourists' willingness to return to a destination under conditions of environmental change, rather than willingness to pay, thereby complementing existing WTP studies and adding an important quantity-based measure to our understanding of tourism demand. Our results can help guide policy by providing insight into how continued environmental degradation might affect return visitation and how changes in resource quality might alter the sociodemographic profile of the Barbados tourist population.

\section{Materials and Methods}

\subsection{Study Site}

Located in the southeastern Caribbean Sea, tourism is the leading foreign exchange earner in Barbados. In 2018, the tourism sector accounted for more than 40 percent of Barbados GDP and national employment [28] and 60.8 percent of total exports. In 2017, Barbados attracted 661,160 overnight tourist arrivals, more than twice its population [29], and a record 681,211 cruise ship passengers [30].

Barbados is among the top-ranking countries for dependence on reefs, yet also among the top countries for highest exposure of the reef to threats [4]. Live coral cover and reef community health have declined considerably since the 1970s [31-33]. These declines have been linked to increasing seawater eutrophication and wastewater pollution from hotels and coastal properties [8,34-39]. Barbados policymakers were prompted to engage in numerous measures, including constructing a 44-km central primary sewage system to capture wastewater flows on the south coast (where hotels are spatially concentrated), implementing water quality standards, forming an oversight committee for water pollution control, and offering tax incentives for upgrades to hotel wastewater disposal systems [6].

Notwithstanding these attempts to translate policy into action, weaknesses remain. The level of sewage treatment in Barbados remains inadequate to protect nearshore ecosystems [6,40], thereby threatening the vital economic contribution of the tourism sector. Indeed, in 2017-2018, a failure at the island's south coast sewage treatment plant resulted in the release of untreated sewage in an area of high tourism activity. As a result, Barbados' main source markets-USA, U.K., Canada and Germany-issued health alerts and travel advisories against visiting Barbados' south coast. Due to health concerns, the government closed Worthing Beach for extended periods from December 2016 to December 2018. Hotels and guest houses in the area have lost business, and several restaurants and shops closed, as many tourists relocated or cancelled reservations.

Policymakers are keenly aware of these problems, but are also concerned about the costs associated with increased waste-water treatment, including disruptions to tourism, transport and 
local commerce [41]. The costs of increasing and maintaining waste-water treatment facilities can be significant, yet are easily calculable for planning purposes. However, because the benefits associated with improved seawater quality and the costs of continued losses have not been quantified, policy makers lack sufficient information to evaluate the economic implications of management interventions or the consequences of inaction. It is this gap in knowledge that this research seeks to address.

\subsection{Survey}

Similar to the approach taken by Hanley et al. [42] and based on prior work in Barbados by Schuhmann et al. $[17,43]$, an exit questionnaire was developed to collect a variety of trip and individual characteristics from departing visitors to Barbados. In addition to providing an array of demographic information such as age, income, country of origin and education level, respondents provided information about their trip, including trip purpose, lodging type, participation in recreational activities in the coastal zone and Likert scale ratings of several coastal and marine attributes.

Early in the survey, respondents were asked to state the likelihood that they would return to Barbados, choosing from "definitely", "probably", "unsure", "probably not" and definitely not". Later in the survey respondents were (again) asked four separate questions about their willingness to return to Barbados, each pertaining to a scenario describing a change in environmental conditions. Specifically, respondents were asked to state the likelihood that they would return to Barbados, choosing from the same responses noted above, if changes occurred to beach width, coral reef health, the quality of marine life (fish, turtles, etc.), and the cleanliness of the sea water. All environmental changes were described in terms of percentage changes from the current condition. The specific text used in the questionnaire is shown in Table 1 below, where we also include corresponding variable names and the coding scheme which ranged from 1-5. The strongest negative response (definitely will not return) was coded as 1 and the strongest positive response (definitely will return) was coded as 5 .

Table 1. Willingness to return survey questions.

\begin{tabular}{cr}
\hline Variable Name & Survey Question (10 Percent Reduction in Quality) \\
\hline Plan_Return & 8. Do you plan to return to Barbados in the future? \\
\hline $\begin{array}{c}\text { Plan to return if beach } \\
\text { width changes } \\
\text { (Plan_Return_BW) }\end{array}$ & $\begin{array}{c}\text { 21. If beach widths in Barbados were to decrease by 10\%, and all other conditions } \\
\text { remained the same, would you return to Barbados in the future? }\end{array}$ \\
\hline $\begin{array}{c}\text { Plan to return if } \\
\text { coral health changes } \\
\text { (Plan_Return_CH) }\end{array}$ & $\begin{array}{c}\text { 22. If coral reef health in Barbados was to decline by 10\%, and all other conditions } \\
\text { remained the same, would you return to Barbados in the future? }\end{array}$ \\
$\begin{array}{c}\text { Plan to return if marine } \\
\text { life changes } \\
\text { (Plan_Return_ML) }\end{array}$ & $\begin{array}{c}\text { 23. If the quality of marine life (fish, turtles, etc.) in Barbados were to decrease by } \\
\text { 10\%, and all other conditions remained the same, would you return to Barbados in } \\
\text { the future? }\end{array}$ \\
\hline $\begin{array}{c}\text { Plan to return if seawater } \\
\text { quality changes } \\
\text { Plan_Return_SW) }\end{array}$ & $\begin{array}{c}\text { 24. If the cleanliness of sea water in Barbados were to change so that your risk of a } \\
\text { stomach infection increased by 10\%, and all other conditions remained the same, } \\
\text { would you return to Barbados in the future? }\end{array}$ \\
\hline $\begin{array}{c}\text { Responses } \\
\text { (data code) }\end{array}$ & Definitely not (1) Probably not (2) Unsure (3) Probably (4) Definitely (5)
\end{tabular}

Sixteen different versions of the survey were randomly distributed among respondents. Each version included one of seven different values of hypothetical environmental changes. Three of these changes were improvements $(5,10$ and 25 percent increases in beach width, coral reef health, marine life and seawater quality) and four described degraded environmental conditions (5, 10, 25 and 50 percent reductions). Due to current trends in Barbados, degradations were deemed more likely than improvements. We therefore weighted the distribution of environmental change parameters toward 
degradations. Roughly 70 percent of respondents were presented with scenarios involving negative changes. Because we used seven values of the environmental change parameter and 16 versions of the survey, the change parameters were not evenly distributed across the sample. For example, -10 and -25 percent changes were presented to 25 percent and 20 percent of the respondents respectively, while the scenario involving 5 percent improvements was presented to 5.5 percent of the sample.

Seawater quality can be expressed in terms of water clarity or visibility [44,45], meeting regulatory standards of quality [42,46], the chance of human illness through contact [47-49] or the presence of algae [44,47]. Water-based recreation can expose individuals to a variety of health hazards arising from contamination by runoff, sewage and excreta [9,49]. According to the World Health Organization [9], enteric illness is the most frequent adverse health outcome associated with exposure to fecally contaminated recreational water. Pond [10] notes that gastroenteric symptoms such as diarrhea are widespread and common among recreational water users. Expressing changes in the quality of seawater in terms of the risk of a stomach infection relative to the status quo condition was judged to be the most appropriate for policy decisions in Barbados.

\subsection{Data}

The questionnaire was distributed to visitors in the departures lounge of the Grantley Adams International Airport (GAIA) in the final two weeks of March 2015. The data were collected prior to the negative publicity surrounding the sewage issues and are a subset of the data used in the Schuhmann et al. analysis of tourists' willingness to pay conservation fees [17]. After removal of incomplete questionnaires and questionnaires that included extreme outliers or illogical responses, approximately 3300 completed questionnaires were retained.

We focus on how responses to the willingness to return questions changed from the first version of the question (status quo conditions, prior to mention of environmental change) to the scenarios that described changes in coastal and marine quality. Because visitation decisions by business travelers (roughly 8 percent of the sample) and Barbadian nationals living abroad (4.7 percent) are likely to be based on non-environmental factors, we removed these two classes of individuals from the sample. Approximately 2700 of the remaining respondents answered both the initial willingness to return question and at least one question regarding willingness to return with changed environmental conditions. From this subsample we remove observations where the respondent initially suggested that they would (would not) return to Barbados, and subsequently indicated a higher probability that they would (would not) return under degraded (improved) environmental conditions. We assume that these respondents did not understand at least one of the willingness to return questions. Our final sample for analysis contains approximately 2550 observations.

\subsection{Empirical Approach}

We use different forms of general linear modeling (GLM) and logit regression to identify factors associated with respondents changing their stated willingness to return to Barbados under status quo conditions (Question 8, Table 1) after being presented with hypothetical changes in environmental quality (Questions 22-24). Changes in the stated intention to return can be measured several ways. First, we can quantify the difference in responses between the two intention to return questions as a single numerical value. For example, a "change in score" measure for changes in intention to revisit following the scenario describing changes in environmental quality can be measured using a new variable, $\mathrm{Y}_{3}$ :

$$
\text { Change_Intention }=\mathrm{Y}_{3}=\mathrm{Y}_{2}-\mathrm{Y}_{1}
$$

where $Y_{1}$ is the response to the initial willingness to return question and $Y_{2}$ is the response to the subsequent question under conditions of environmental change. This variable can be constructed for changes in water quality, beach width, coral reef health and the quality of marine life, and is an ordinal variable with nine theoretically possible outcomes ranging from -4 to 4 . Negative values of 
Change_Intention correspond to potential losses (respondents who are less likely to return), while positive values represent potential gains in return visitation (respondents who are more likely to return). A larger absolute value indicates a higher magnitude of change from the initial stated response. Table 2, below, shows the possible composition of values for Change_Intention outcomes.

Table 2. Composition of values for Change_Intention Score.

\begin{tabular}{|c|c|c|c|c|c|}
\hline \multicolumn{6}{|c|}{ Change_Intention_XX $=$ Plan_Return_XX ${ }^{a}-$ Plan_Return } \\
\hline \multirow{4}{*}{ Losses } & -4 & \multicolumn{4}{|c|}{ Definitely No - Definitely Yes } \\
\hline & -3 & \multicolumn{2}{|c|}{ Probably No - Definitely Yes } & \multicolumn{2}{|c|}{ Definitely No - Probably Yes } \\
\hline & -2 & Unsure - Definitely Yes & \multicolumn{2}{|c|}{ Probably No - Probably Yes } & Definitely No - Unsure \\
\hline & -1 & Def. No - Prob. No & Prob No - Unsure & Unsure - Prob. Yes & Prob. Yes - Def. Yes \\
\hline & 0 & \multicolumn{4}{|c|}{ No Change } \\
\hline \multirow{4}{*}{ Gains } & 1 & Def. Yes - Prob. Yes & Prob Yes - Unsure & Unsure - Prob. No & Prob. No - Def. No \\
\hline & 2 & Definitely Yes - Unsure & \multicolumn{2}{|c|}{ Probably Yes - Probably No } & Unsure - Definitely No \\
\hline & 3 & \multicolumn{2}{|c|}{ Probably Yes - Definitely No } & \multicolumn{2}{|c|}{ Definitely Yes - Probably No } \\
\hline & 4 & \multicolumn{4}{|c|}{ Definitely Yes - Definitely No } \\
\hline
\end{tabular}

${ }^{a} \mathrm{XX}$ is a placeholder for the four environmental changes examined in our survey: beach width $(B W)$, coral health $(\mathrm{CH})$, marine life $(M L)$ and seawater $(S W)$.

Alternatively, we can analyze indicator variables representing different discrete response changes, such as changing the stated intention to return from "definitely yes" (DY) to "definitely not" (DN), or variables that represent groupings of response changes such as changing from "definitely yes" or "probably yes" (DPY) to "definitely not" or "probably not" (DPN):

$$
\begin{gathered}
Y_{D Y D N}=1, \text { if } Y_{1}=5 \text { and } Y_{2}=1 ;\left(Y_{3}=4\right) \\
Y_{D Y D N}=0 \text {, otherwise } \\
Y_{\text {DPYDPN }}=1, \text { if } Y_{1} \geq 4 \text { and } Y_{2} \leq 2, \\
Y_{\text {DPYDPN }}=0 \text {, otherwise }
\end{gathered}
$$

The first step in our approach is to use correlation analysis and analysis of variance (ANOVA) to understand whether the values for Change_Intention are associated with the different values of environmental change presented in the survey. The second step is to use various forms of regression modeling to identify factors that are associated with changes in the stated intention to revisit.

A simple approach to modeling change in stated response is to use linear regression (an ordered logit specification would require conversion of Change_Intention to a value ranging from 0-8 rather than $-4-4$, and consequently the treatment of 0 as "no change" would not be preserved) to model Change_Intention as a function of the value of environmental change presented to the respondent, $\mathrm{c}_{\mathrm{i}}$, and individual characteristics, $\mathrm{X}_{\mathrm{i}}$ :

$$
Y_{3}=\left(Y_{2}-Y_{1}\right)=\beta_{0}+\beta_{1} c_{i}+\Sigma \beta X_{i}+\varepsilon_{i}
$$

An important consideration is whether to include the initial willingness to return response $\left(\mathrm{Y}_{1}\right.$,Plan_Return) as a control variable in Equation (4). Including such a control ensures that any response changes are truly associated with other explanatory variables and not the result of differences in the initial response across groups in the sample. For example, if visitors from the U.S. are initially more likely to state a high probability of return $\left(\mathrm{Y}_{1}\right)$ relative to visitors from other countries, values of Change_Intention may be lower (more negative) for visitors from the U.S., all else being equal. Analysis of Change_Intention without the baseline response control might then lead to the erroneous conclusion that visitors from the U.S. are more sensitive to environmental change. After exploring the relationship 
between the initial willingness to return response $\left(Y_{1}\right)$ and other respondent factors, we include $Y_{1}$ as a baseline control variable in modeling response change.

Another consideration for the model in Equation (4) is the assumption that the effect of environmental change, $c_{i}$, on Change_Intention can be captured by a single linear coefficient $\beta_{1}$. To examine whether the effect of environmental change on Change_Intention is non-linear, we can include a quadratic term, $\mathrm{ci}_{\mathrm{i}}{ }^{2}$, in Equation (4) or treat the alternative values of $\mathrm{c}_{\mathrm{i}}$ as indicator variables.

As an alternative to modeling the change in intention to return as a continuous variable, binary response models such as logit regression can be used to understand factors that are associated with discrete changes such as those shown in Equation (2) or Equation (3). An individual i can be expected to change their stated revisit intention in response to an environmental change if their expected utility (satisfaction) $\mathrm{U}_{\mathrm{i}}$ under the new revisit intention is higher than utility with the initial revisit intention:

$$
\mathrm{U}_{1 \mathrm{i}}\left(\mathrm{V}_{1 \mathrm{i}}+\varepsilon_{1 \mathrm{i}}\right) \geq \mathrm{U}_{0 \mathrm{i}}\left(\mathrm{V}_{0 \mathrm{i}}+\varepsilon_{0 \mathrm{i}}\right)
$$

where $U_{i}$ represents the respondent's utility, which is comprised of an observable (deterministic) component $\mathrm{V}_{\mathrm{i}}$ and an unobservable (stochastic) component $\varepsilon_{\mathrm{i}}$.

The probability of changing responses to the willingness to return questions is therefore the probability that expected utility under the new conditions exceeds utility under the original (status quo) conditions. For example, the probability that an individual would change from "definitely will return" to "definitely will not return" is the probability that expected utility with certain intentions to not revisit $\left(\mathrm{U}_{1}\right)$ is higher than expected utility with certain intentions to revisit $\left(\mathrm{U}_{0}\right)$ :

$$
P_{\mathrm{i}}\left(\mathrm{Y}_{\mathrm{DYDN}}\right)=\mathrm{P}_{\mathrm{i}}\left(\mathrm{Y}_{3}=-4\right)=\mathrm{P}\left[\mathrm{U}_{1 \mathrm{i}}\left(\mathrm{V}_{1 \mathrm{i}}+\varepsilon_{1 \mathrm{i}}\right) \geq \mathrm{U}_{0 \mathrm{i}}\left(\mathrm{V}_{0 \mathrm{i}}+\varepsilon_{0 \mathrm{i}}\right)\right]
$$

To estimate probabilities such as Equation (6) using logit regression, we assume that utility is linear in the degree of environmental change presented to the respondent, $\mathrm{c}_{\mathrm{i}}$, and other respondent characteristics, $X_{\mathrm{i}}$ :

$$
\mathrm{U}_{\mathrm{i}}\left(\mathrm{c}_{\mathrm{j}}, \mathrm{X}_{\mathrm{i}}\right)=\beta_{0}+\beta_{1} \mathrm{c}_{\mathrm{i}}+\Sigma \beta \mathrm{X}_{\mathrm{i}}+\varepsilon_{\mathrm{i}}
$$

For the logit specification, the probability shown in Equation (6) is then given by:

$$
P_{i}\left(Y_{D Y D N}\right)=\frac{\exp \left(\beta_{0}+\beta_{1} c_{i}+\Sigma \beta X_{i}\right)}{1+\exp \left(\beta_{0}+\beta_{1} c_{i}+\Sigma \beta X_{i}\right)}
$$

A consideration when examining response changes such as changing from "definitely will return" to "definitely will not return", is whether to limit the sample to respondents who were presented with scenarios involving negative environmental change. Respondents who were presented environmental improvements would not logically change from "will return" to "will not return", but will be coded as 0 in formulations of the dependent variable such as Equations (2) and (3), indicating that they did not make this change. Inclusion of these respondents may therefore confound the estimation of the coefficients on respondent characteristics. We explore Equation (8) using both the full sample and the subsample of respondents who faced scenarios involving negative environmental change.

\section{Results}

\subsection{Summary Statistics}

Visitors from the United States and Canada were over-represented in the sample relative to annual arrivals from Barbados' main source markets in 2015 (34\% and 18\% in our sample vs. $23 \%$ and $13 \%$ annual arrivals in 2015). Visitors from the U.K., the Caribbean and other European countries were under-represented (approximately $34 \%, 8 \%$ and $3 \%$ in our sample vs. $35 \%, 16 \%$ and $8 \%$ of annual 2015 arrivals). To accurately represent the preferences of the population of visitors by main source market, 
each observation was weighted using the ratio of the actual to sample percentage of visitors from each main market per year. All results presented below are based on the weighted sample.

Summary statistics are shown in Table 3. Notably, approximately 52 percent of the sample was visiting Barbados for the first time. Of those who had been to Barbados on a prior occasion, the average number of prior trips was approximately 6.5. Summary statistics for participation in coastal and marine recreation activities and ratings of coastal and marine quality are shown in Table 4 . Respondents were heavily involved in coastal and marine recreation, with swimming, snorkeling and swimming with turtles being the most common activities. Respondents provided high ratings for all aspects of coastal and marine quality, with the quality of sand on beaches and the cleanliness and visibility of seawater receiving the highest average ratings and beach width receiving the lowest average rating.

Table 3. Descriptive statistics for respondent characteristics.

\begin{tabular}{|c|c|c|c|c|c|c|}
\hline Variable & Definition & $\mathbf{n}$ & Mean & Std Dev & Minimum & Maximum \\
\hline $\begin{array}{l}\text { Environmental } \\
\text { Change }\end{array}$ & $\begin{array}{c}\text { Degree of environmental } \\
\text { change presented in scenario }\end{array}$ & 2548 & -10.84 & 20.96 & -50 & 25 \\
\hline $\begin{array}{l}\text { First visit to } \\
\text { Barbados }\end{array}$ & $\begin{array}{c}=1 \text { if respondent is had visited } \\
\text { Barbados on a prior occasion } \\
\quad=0 \text { otherwise }\end{array}$ & 2538 & 0.52 & 0.49 & 0 & 1 \\
\hline $\begin{array}{l}\text { Times to } \\
\text { Barbados }\end{array}$ & $\begin{array}{l}\text { Number of prior trips to } \\
\text { Barbados }\end{array}$ & 2476 & 3.02 & 6.31 & 0 & 100 \\
\hline US Resident & $\begin{array}{c}=1 \text { if the respondent is from } \\
\text { the US } \\
=0 \text { otherwise }\end{array}$ & 2548 & 0.24 & 0.42 & 0 & 1 \\
\hline UK Resident & $\begin{array}{c}=1 \text { if the respondent is from } \\
\text { the U.K. } \\
=0 \text { otherwise }\end{array}$ & 2548 & 0.41 & 0.48 & 0 & 1 \\
\hline $\begin{array}{l}\text { Canadian } \\
\text { Resident }\end{array}$ & $\begin{array}{c}=1 \text { if the respondent is from } \\
\text { Canada } \\
=0 \text { otherwise }\end{array}$ & 2548 & 0.14 & 0.34 & 0 & 1 \\
\hline Europe Resident & $\begin{array}{c}=1 \text { if the respondent is from } \\
\text { other European country } \\
=0 \text { otherwise }\end{array}$ & 2548 & 0.08 & 0.26 & 0 & 1 \\
\hline $\begin{array}{l}\text { Caribbean } \\
\text { Resident }\end{array}$ & $\begin{array}{c}=1 \text { if the respondent is from } \\
\text { the Caribbean } \\
=0 \text { otherwise }\end{array}$ & 2548 & 0.09 & 0.28 & 0 & 1 \\
\hline $\begin{array}{l}\text { Higher } \\
\text { Education }\end{array}$ & $\begin{array}{l}=1 \text { if the respondent had at } \\
\text { least some college education } \\
=0 \text { otherwise }\end{array}$ & 2548 & 0.56 & 0.49 & 0 & 1 \\
\hline
\end{tabular}


Table 4. Summary statistics for participation in coastal and marine recreation and ratings of quality.

\begin{tabular}{cccccc}
\hline Variable & $\mathbf{n}$ & Mean & Std Dev & Minimum & Maximum \\
\hline \multicolumn{1}{c}{ Participation in Recreational Activities } & & \\
\hline Visited the Beach (\%) & 2459 & 0.92 & 0.27 & 0 & 1 \\
Went Swimming (\%) & 2493 & 0.79 & 0.39 & 0 & 1 \\
Snorkeled (\%) & 2493 & 0.42 & 0.48 & 0 & 1 \\
Went Swimming with Turtles (\%) & 2493 & 0.37 & 0.47 & 0 & 1 \\
Went Sailing (\%) & 2493 & 0.26 & 0.43 & 0 & 1 \\
Went Jet Skiing (\%) & 2461 & 0.08 & 0.26 & 0 & 1 \\
Went Power Boating (\%) & 2493 & 0.07 & 0.24 & 0 & 1 \\
Went Scuba Diving (\%) & 2493 & 0.04 & 0.19 & 0 & 1 \\
\hline 5-point Likert Scale Ratings of Coastal/Marine Quality & & \\
1 = "lowest quality”, $5=$ “highest quality” & & 5 \\
Quality of Sand on Beaches & 2475 & 4.40 & 0.84 & 1 & 5 \\
Cleanliness and Visibility of Seawater & 2441 & 4.35 & 0.89 & 1 & 5 \\
Natural Character of Beaches & 2428 & 4.31 & 0.84 & 1 & 5 \\
Ease of access to beaches & 2445 & 4.31 & 0.92 & 1 & 5 \\
Ease of getting in and out of the sea & 2344 & 4.21 & 0.93 & 1 & 5 \\
Cleanliness of Beaches & 2484 & 4.19 & 0.93 & 1 & 5 \\
Quality of coral reefs and marine life & 1541 & 4.00 & 0.92 & 1 & 5 \\
Width of Beaches & 2449 & 3.97 & 0.97 & 1 & \\
\hline
\end{tabular}

Responses to the willingness to return questions are summarized in Table 5, which includes summary statistics for responses to the original willingness to return question, the follow-up questions involving environmental change and the Change_Intention variables. It is notable that changes in the quality of seawater induced significantly more changes in respondents' stated intention to return to Barbados than the other three environmental changes presented.

Table 5. Descriptive statistics for stated intention to return and Change_Intention.

\begin{tabular}{ccccccc}
\hline \multirow{2}{*}{} & Variable & N & Mean & Std Dev & Minimum & Maximum \\
\hline \multirow{4}{*}{ Original stated } & Plan_Return & 2578 & 4.33 & 0.80 & 1 & 5 \\
intention to return & Definitely not & 2578 & 0.005 & 0.07 & 0 & 1 \\
& Probably not & 2578 & 0.05 & 0.21 & 0 & 1 \\
& Unsure & 2578 & 0.06 & 0.23 & 0 & 1 \\
& Probably & 2578 & 0.41 & 0.48 & 0 & 1 \\
& Definitely & 2578 & 0.49 & 0.49 & 0 & 1 \\
\hline \multirow{2}{*}{ Intention to return } & Plan_Return_SW & 2577 & 2.94 & 1.43 & 1 & 5 \\
with environmental & Plan_Return_ML & 2561 & 3.68 & 1.67 & 1 & 5 \\
change & Plan_Return_CH & 2544 & 3.79 & 1.08 & 1 & 5 \\
& Plan_Return_BW & 2561 & 3.85 & 1.06 & 1 & 5 \\
\hline \multirow{2}{*}{ Change in intention to } & Change_Intention_SW & 2577 & -1.39 & 1.45 & -4 & 3 \\
return with & Change_Intention_ML & 2561 & -0.65 & 1.07 & -4 & 3 \\
environmental change & Change_Intention_CH & 2544 & -0.53 & 0.95 & -4 & 3 \\
& Change_Intention_BW & 2561 & -0.47 & 0.89 & -4 & 2 \\
\hline
\end{tabular}

In Table 6, we show the percentage of respondents who changed their stated intentions to return to Barbados (i.e., the value of Change_Intention shown in Table 2 is not 0 ) by degree of environmental change. As expected, higher degrees of environmental change result in more respondents changing their stated intention to return. Two notable results are apparent from this Table. First, as illustrated in Table 5, significantly fewer respondents maintained their original willingness to return in response to changes in seawater quality relative to the other environmental changes presented. Even the smallest decline in water quality (5 percent higher chance of an infection) resulted in over 70 percent 
of respondents changing their response. Of the 352 respondents who were presented with the scenario involving a 50 percent reduction in water quality, 18 percent had the most severe change in intentions to revisit, changing their response from "definitely will return" to "definitely will not return" (Change_Intention_SW =-4). Another 44 percent changed from "definitely will return" to "probably will not return" or from "probably will return" to "definitely will not return" (Change_Intention_SW = -3). Hypothetical improvements in environmental quality did not influence the stated intention to return to Barbados for a large majority of respondents.

Table 6. Percentage of respondents who changed stated intention to return to Barbados, by severity of environmental change.

\begin{tabular}{ccccc}
\hline $\begin{array}{c}\text { Environmental } \\
\text { Change }\end{array}$ & $\begin{array}{c}\text { Cleanliness \& Visibility } \\
\text { of Seawater }(S W)\end{array}$ & $\begin{array}{c}\text { Quality of } \\
\text { Marine Life }(\mathbf{M L})\end{array}$ & Coral Health $(\boldsymbol{C H})$ & Beach Width $(\boldsymbol{B W})$ \\
\hline-50 & 90.96 & 66.02 & 60.22 & 61.50 \\
-25 & 83.20 & 58.53 & 53.48 & 48.31 \\
-10 & 76.87 & 46.45 & 41.65 & 35.60 \\
-5 & 71.85 & 44.21 & 40.36 & 31.36 \\
5 & 6.77 & 7.52 & 6.77 & 6.02 \\
10 & 9.57 & 12.06 & 10.28 & 6.38 \\
25 & 11.61 & 12.36 & 12.36 & 10.11 \\
\hline
\end{tabular}

\subsection{General Linear Models of Change_Intention Score}

Correlation coefficients between the change intention variables (Table 2) and the degree of environmental change suggest significant positive correlations between these measures (Pearson correlation coefficients are $0.57,0.41,0.41$ and 0.39 for changes in seawater quality, beach width, marine life and coral health respectively. All correlation coefficients are statistically significant at the $\alpha=0.01$ level). Higher (lower) values of environmental change (which ranges from -50 to +25 ) are associated with higher (lower) values of Change_Intention (which ranges from -4 to +4 ). t-tests show that all values of environmental change resulted in statistically significant changes in responses for all environmental quality measures (all mean values of Change_Intention were statistically different than zero at the $\alpha=0.01$ level for each level of environmental change). These results suggest that respondents changed their stated willingness to return in response to the hypothetical scenarios in the expected direction.

Analysis of variance (ANOVA) for differences in the Change_Intention variable for each pair of values of environmental change revealed no significant differences in Change_Intention for any pair of positive environmental changes. In other words, while environmental improvement scenarios caused respondents to change their stated intention to return in the expected (more favorable) direction, respondents did not react differently to 5 percent, 10 percent or 25 percent improvements in any of the environmental changes. Furthermore, we find no statistically significant differences in Change_Intention between 5 and 10 percent declines in beach width, coral health or the quality of marine life, or between 25 and 50 percent declines in coral health. Highly significant differences in Change_Intention were found for all other pairs of environmental change.

Numerous combinations of explanatory variables were tested in a GLM regression framework for Change_Intention. The environmental change variable was included as a continuous variable, a quadratic variable and using six indicator variables. Results shown in Table 7 are representative and include variables of policy interest (e.g., degree of environmental change, whether the respondent is a first-time visitor, respondent country of origin) and those that were found to be robust to specification. Because of the potential for biased estimates due to multicollinearity between the extensive and intensive margins of past visitation (i.e., the indicator variable for first time visitor and the number of prior visits), we examine model specifications that include both measures together and separately. 
Table 7. General linear regression coefficient estimates. Dependent variable is Change_Intention_XX.

\begin{tabular}{|c|c|c|c|c|}
\hline Parameter & Seawater & Beach Width & Coral Health & Marine Life \\
\hline Intercept & $2.65^{* * *}$ & $1.05^{* * *}$ & $1.46^{* * *}$ & $1.59^{* * *}$ \\
\hline Plan_Return & $-0.50 * * *$ & $-0.24^{* * *}$ & $-0.31^{* * *}$ & $-0.37^{* * *}$ \\
\hline envchange -50 & $-2.56^{* * *}$ & $-1.15^{* * *}$ & $-1.24^{* * *}$ & $-1.50^{* * *}$ \\
\hline envchange -25 & $-2.12 * * *$ & $-0.85^{* * *}$ & $-1.04^{* * *}$ & $-1.22 * * *$ \\
\hline envchange -10 & $-1.79 * * *$ & $-0.58^{* * *}$ & $-0.87^{* * *}$ & $-1.10^{* * *}$ \\
\hline envchange -5 & $-1.61^{* * *}$ & $-0.51^{* * *}$ & $-0.74^{* * *}$ & $-0.90^{* * *}$ \\
\hline envchange +5 & 0.03 & 0.02 & -0.06 & -0.07 \\
\hline envchange +10 & 0.05 & -0.01 & 0.02 & 0.04 \\
\hline Quality Rating a & -0.001 & $0.08^{* * *}$ & $0.06^{* *}$ & $0.06^{* *}$ \\
\hline $\begin{array}{l}\text { First Visit to } \\
\text { Barbados }\end{array}$ & -0.02 & -0.04 & $-0.15^{* * *}$ & $-0.13^{* *}$ \\
\hline $\begin{array}{c}\text { Previous trips to } \\
\text { Barbados }\end{array}$ & $0.01^{+}$ & 0.002 & 0.001 & $0.01 *$ \\
\hline US Resident & $-0.22 * * *$ & $-0.18^{* * *}$ & -0.09 & 0.01 \\
\hline UK Resident & $-0.12 *$ & -0.04 & -0.06 & 0.06 \\
\hline Canada Resident & -0.10 & -0.09 & -0.07 & 0.07 \\
\hline Caribbean Resident & -0.16 & $-0.18^{* *}$ & -0.13 & -0.03 \\
\hline Went Swimming & 0.02 & $-0.10^{* *}$ & 0.03 & 0.03 \\
\hline Went to the Beach & $-0.16^{*}$ & 0.04 & 0.03 & 0.07 \\
\hline Snorkeled & $-0.11^{* *}$ & -0.02 & -0.06 & $-0.11^{* *}$ \\
\hline Higher Education & $-0.21^{* * *}$ & $-0.12^{* * *}$ & $-0.13^{* * *}$ & $-0.12^{* *}$ \\
\hline $\mathrm{n}$ & 2348 & 2344 & 1480 & 1483 \\
\hline $\mathrm{R}^{2}$ & 0.50 & 0.249 & 0.280 & 0.308 \\
\hline
\end{tabular}

,$+ * * *$, and ${ }^{* * *}$ indicate statistical significance at the $15 \%, 10 \%, 5 \%$ and $1 \%$ levels respectively. Standard errors not shown to save space. ${ }^{a}$ Quality ratings are 5-point Likert scale ratings of cleanliness and visibility of seawater, beach width and the quality of corals and marine life.

In Table 7, positive (negative) coefficients indicate that higher values of the corresponding independent variable are associated with higher (lower) values of Change_Intention. For example, the negative coefficient on Plan_Return suggests that respondents who originally stated a higher probability of returning to Barbados were more likely to change in the negative direction (i.e., suggest a lower likelihood of return under conditions of environmental change).

Respondents who were presented with scenarios involving environmental losses were more likely to change their intention to return in the negative direction. On average, a higher magnitude of any form of environmental loss induces higher change in response, signaling that tourists are sensitive to declines in coastal and marine quality. In contrast, environmental improvement scenarios do not appear to induce significant change in stated intention to return. When coded as a continuous variable, coefficients on the environmental change variable were consistently positive and highly statistically significant, consistent with the results in Table 7. Including a quadratic term for environmental change in the specification (independently or in combination with the linear term) confirms that this relationship is nonlinear.

Tourists' nationality appears to explain differences in the responsiveness towards environmental degradation. Residents of the U.S. and U.K. appear more sensitive to changes in water quality, while U.S. and Caribbean visitors appear more responsive to reductions in beach width. We find no apparent differences in sensitivity to changes in coral health or marine life across nationalities. Respondents 
who provided higher Likert scale ratings of beach width, coral health or marine life are less likely to change their stated intention to return in response to changes in those aspects of environmental quality, implying that environmental losses are less of a deterrent for return visitation for tourists who are satisfied with these environmental conditions.

In terms of destination loyalty, first time visitors appear more sensitive to changes in coral health and marine life than repeat visitors, suggesting that repeat visitors are less likely to change their stated intentions to return following changes in these aspects of environmental quality. We also find mild evidence that respondents with more previous trips to Barbados are less sensitive to changes in seawater quality. That is, all else being equal, degradations in seawater quality are likely to have a smaller impact on return decisions for frequent visitors to Barbados.

All recreation activities shown in Table 4 were included as covariates, independently and in combination. Only swimming, going to the beach and snorkeling were found to be significantly associated with Change_Intention. It is notable that snorkelers appear to be more sensitive to changes in sea water quality and the quality of marine life than non-snorkelers. Finally, we find that respondents with higher education are more sensitive to all environmental changes than those without higher education.

To illustrate the differential impact of environmental change scenarios on respondents' stated intention to return, we plot fitted values of Change_Intention across all levels of environmental change using the coefficient estimates shown in Table 7. We calculate fitted values for a first-time visitor from the U.S. with a college education, who went to the beach, went swimming and snorkeling, and provided the highest ratings of environmental quality. The shapes of the functions in Figure 1 illustrate the nonlinear relationship between degree of environmental change and the magnitude of response in stated intention to return.

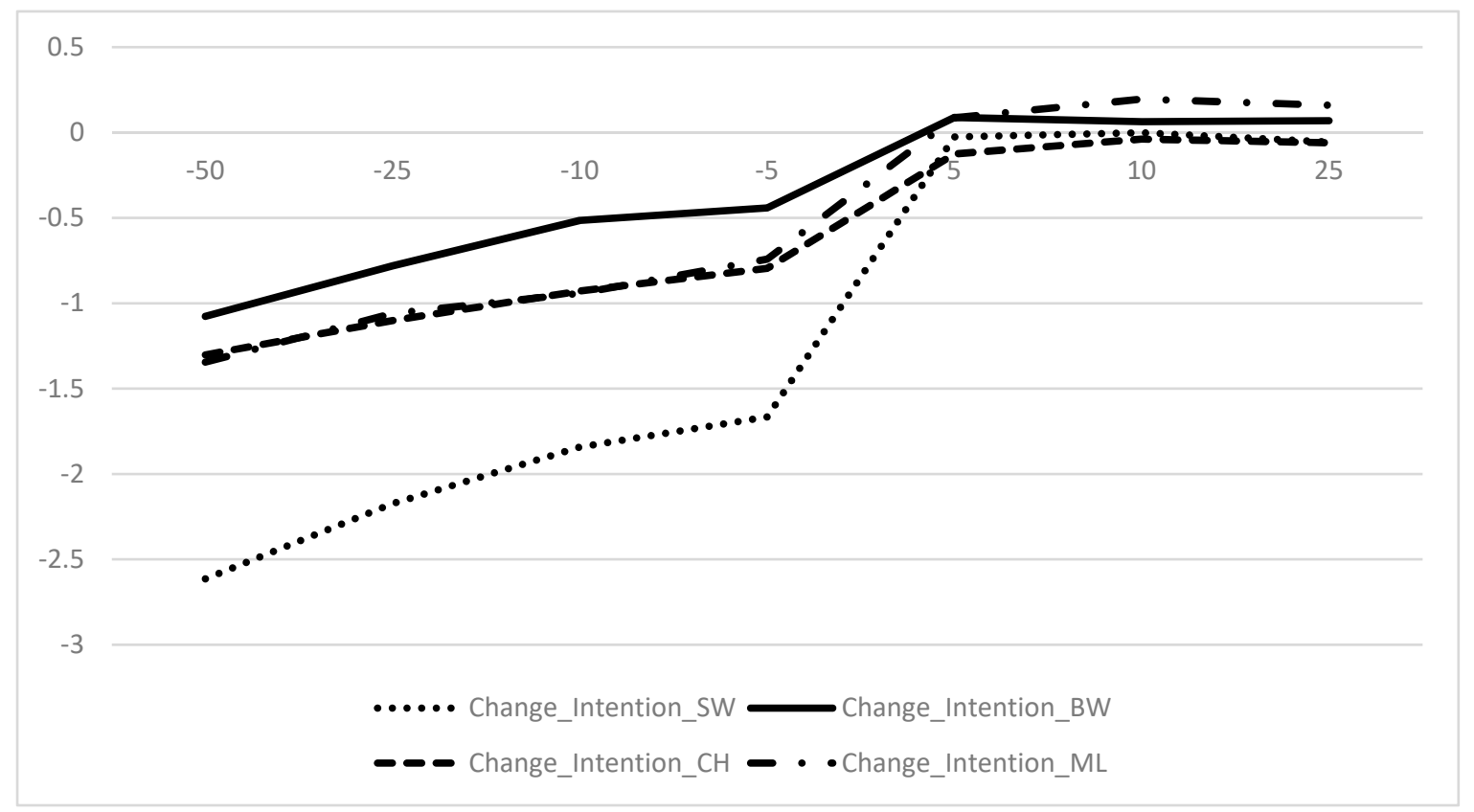

Figure 1. Predicted value of Change_Intention for different levels of environmental change. The value of Change_Intention measured on $Y$-axis. Degree of environmental change measured on $X$-axis.

\subsection{Logit Models of Intention to Return}

We use logit regression to identify the factors that are associated with discrete changes in stated intention to return. As shown in Table 2, above, respondents could change their stated intention to return in 20 distinct ways in response to hypothetical changes in environmental quality (10 for improvements in quality and 10 for declines). Because environmental improvements have little impact 
on stated intention to return, we restrict the sample to respondents who viewed scenarios involving reductions in quality.

Table 8 shows the results of logit regression models for changing responses from "definitely" or "probably" will return to "definitely" or "probably" will not return (i.e., the dependent variable is equal to one if the respondent changed their stated intention from "definitely" or "probably" will return to "definitely" or "probably" will not return, and equal to zero otherwise). Numerous model specifications and combinations of covariates were estimated. The results presented in Table 8 are representative. We also examined less severe changes, such as changing from "definitely will return" to "definitely" or "probably" will not return and found results very similar to those presented in Table 8. Limited responses for the most severe unfavorable change ("definitely will return" to "definitely will not return") inhibited maximum likelihood estimation.

Table 8. Logit regression coefficient estimates. Dependent variable $=1$ if respondent changed response from "definitely" or "probably" will return to "definitely" or "probably" will not return.

\begin{tabular}{|c|c|c|c|c|}
\hline Parameter & Seawater & Beach Width & Coral Health & Marine Life \\
\hline Intercept & $-4.23 * * *$ & $-3.51^{* * *}$ & $-3.50 * * *$ & $-3.09 * * *$ \\
\hline Plan_Return & $0.75^{* * *}$ & $0.24^{* *}$ & $0.35^{* * *}$ & $0.47^{* * *}$ \\
\hline envchange -50 & $1.42^{* * *}$ & $1.45^{* * *}$ & $1.22 * * *$ & $1.19^{* * *}$ \\
\hline envchange -25 & $0.83 * * *$ & $0.74 * * *$ & $0.77^{* * *}$ & $0.77^{* * *}$ \\
\hline envchange -10 & $0.36^{* *}$ & 0.17 & $0.60 * *$ & $0.65^{* * *}$ \\
\hline Quality Rating & -0.05 & $-0.29 * * *$ & $-0.19^{* *}$ & $-0.14^{*}$ \\
\hline First Visit to Barbados & 0.18 & $0.39 * *$ & $0.80^{* * *}$ & $0.52 * * *$ \\
\hline Previous trips to Barbados & $-0.02 * *$ & 0.0005 & 0.01 & -0.02 \\
\hline US Resident & $0.39 * *$ & $0.88^{* * *}$ & -0.14 & -0.34 \\
\hline UK Resident & $0.37^{* *}$ & $0.49 *$ & -0.13 & $-0.41 *$ \\
\hline Canada Resident & $0.42^{* *}$ & $0.68^{* *}$ & 0.13 & -0.25 \\
\hline Caribbean Resident & $0.46^{*}$ & $0.72 *$ & 0.12 & -0.08 \\
\hline Went Swimming & -0.16 & $0.52 * *$ & -0.17 & -0.16 \\
\hline Went to the Beach & $0.41 *$ & -0.11 & -0.03 & -0.35 \\
\hline Snorkeled & $0.36^{* * *}$ & 0.01 & 0.22 & $0.36^{* *}$ \\
\hline Higher Education & $0.35^{* * *}$ & 0.17 & 0.24 & 0.17 \\
\hline $\mathrm{n}$ & 1723 & 1722 & 1070 & 1073 \\
\hline$\%$ of Respondents who changed & 60.5 & 16.1 & 19.1 & 25.6 \\
\hline AIC & 2057.57 & 1313.73 & 961.17 & 1125.27 \\
\hline $2 \log L$ & 2025.57 & 1281.73 & 929.17 & 1093.27 \\
\hline
\end{tabular}

$+^{*}, * *$, and ${ }^{* * *}$ indicate statistical significance at the $15 \%, 10 \%, 5 \%$ and $1 \%$ levels, respectively. Standard errors not shown to save space. ${ }^{\text {a }}$ Quality ratings are 5-point Likert scale ratings of cleanliness and visibility of seawater, beach width and the quality of corals and marine life.

In these models, positive (negative) and statistically significant coefficients indicate that higher (lower) values of the variable are associated with a higher probability of changing the stated intention to return. For example, the coefficients on 50 and 25 percent environmental losses are consistently positive and highly significant. This indicates that these changes in environmental quality are associated with a higher probability of changing the stated intention to return to Barbados from "definitely" or "probably" will return to "definitely" or "probably" will not return. The positive coefficient on Plan_Return suggest that respondents who originally stated a higher probability of returning to Barbados were more likely to suggest a lower likelihood of return under conditions of environmental change. 
As with Change_Intention, higher magnitudes of any form of environmental loss are associated with a higher probability that respondents change their stated intention to return. Again, we find nationality appears to explain differences in the response variable. Residents of the U.S., U.K. and Canada appear more sensitive to changes in water quality and beach width, and Caribbean residents appear to have similar but less significant tendencies to change response. We also find no significant differences in sensitivity to changes in coral health or marine life across main market points of origin, except for a mild reaction by U.K. residents to changes in marine life. Also supporting the above analysis of Change_Intention, environmental losses are less likely to affect return visitation for tourists who are satisfied with beach width, coral health or marine life, and snorkelers appear to be more sensitive to changes in sea water quality and the quality of marine life than non-snorkelers. We again find evidence of destination loyalty. First time visitors are more sensitive to changes in beach width, coral health and marine life than repeat visitors. Interestingly, first time visitors appear most sensitive to changes in coral health. Respondents with more previous trips to Barbados are again found to be less sensitive to changes in seawater quality.

\section{Discussion}

This research demonstrates that Barbados tourists' return visitation decisions are sensitive to declines in all aspects of coastal and marine quality. This general finding was expected, given that tourists' major attractions to Barbados are "sea, sand and sun" products and that tourists require value for their money. Of the four coastal and marine attributes examined, declines in seawater quality have the most significant impact on tourists' stated willingness to return, confirming the notion that perceived risks involving water-based recreation have important economic repercussions in tourism-dependent areas [10].

It is notable that even the highest levels of losses in beach width, coral health and marine life (i.e., 50\% losses) do not produce as dramatic an impact on return visitation intentions as the smallest change in seawater quality (i.e., $5 \%$ higher probability of an infection). This finding is consistent with the results of Can and Alp, who find that tourists and residents are willing to pay more for water quality than improvements in marine life in Turkey [48], and Halkos and Matsiori, who find that improving the quality of bathing water is the most important determinant of willingness to pay for coastal zone improvement in Volos, Greece [14]. A possible explanation is that recreationists understand that seawater quality has a direct impact on their health, whereas attributes such as beach width, coral health and marine life are primarily associated with aesthetic enjoyment. It may also be the case that the quality of seawater has an impact on the aesthetic value and perception of reef quality and marine life; however, our data do not allow for testing of this hypothesis.

Another salient takeaway from this research is that scenarios involving environmental improvements do not result in statistically significant changes in tourists' stated intention to return. We can infer that tourists are averse to environmental losses, a result that may be an artifact of general loss aversion or an endowment effect. It may also be the case that respondents' expectations for environmental quality have largely been met. Ratings of coastal and marine quality were generally high, and those who found environmental quality to be favorable were less deterred by losses in quality. Satisfied with current conditions, further improvements do not induce significant changes in tourists' intentions to revisit. An important policy implication is that if the economic costs of improving environmental quality are prohibitive, maintaining status quo conditions might be enough to support continued tourism demand. It is important to note that this result stands in contrast to numerous monetary valuation studies that show positive WTP for improvements in coastal and marine quality $[14,21-23,43]$, and illustrates the importance of understanding both price and quantity aspects of the demand relationship. It seems clear from the literature that people are WTP higher prices for trips with improved environmental quality, but it may be the case that such improvements would not induce a change in the number of trips demanded. This suggests that destinations can capture 
economic surplus from environmental improvements through pricing mechanisms, but not necessarily through increased visitation. Further research in this area appears warranted.

We find that first time visitors are more sensitive to changes in coral health and marine life than return visitors. It may be the case that repeat visitors have established stronger ties to the community and tend to visit for reasons beyond coastal and marine quality. This inference aligns with the marketing notion that it is harder to attract a new visitor than retain an existing one [12,50,51]. Existing repeat tourists have developed destination loyalty and may be harder to sway away from a familiar or preferred destination [52]. It is, therefore, not surprising that increased frequency of visitation (number of prior visits) reduces visitors' sensitivity to some environmental losses.

Respondents with higher education appear to be more sensitive to all losses in environmental quality and are especially sensitive to declines in seawater quality. More educated tourists may be more aware of environmental issues and the impact of environmental degradation on their health, thus having a higher aversion to adverse environmental effects. Furthermore, more educated tourists may be more aware of or more able to afford alternative destinations where environmental conditions are relatively favorable [14]. Importantly, we find that tourists in our sample with higher educations are younger, have higher incomes, and spend more on their trips to Barbados (all differences are highly statistically significant $(\alpha<0.01)$ ). Our results therefore imply that continued deterioration of coastal and marine quality in Barbados may shift the demographic profile of tourists toward individuals who are less educated, less likely to engage in marine recreation and have lower economic impact while on island. Given our findings regarding nationality and stated intention to return, it also seems likely that continued losses in coastal and marine quality will result in lower return visitation from the U.K. and the U.S., Barbados' two main source markets.

Our findings are consistent with other results in the literature. For example, of the four coastal and marine attributes examined in Schuhmann et al. [44], tourists' WTP is least sensitive to changes in beach width and are only willing to pay to avoid very narrow beaches. We find that tourists who are more satisfied with environmental attributes are less sensitive to declines environmental quality, supporting the results of $\mathrm{Um}$ et al., who find that perceived attractiveness serves as a strong predictor of intention to revisit [50]. Our results suggest that visitation decisions by respondents who had recreational contact with coastal and marine environments (particularly through snorkeling) were more sensitive to environmental change than those who did not engage in these activities. This is consistent with results found by Beharry-Borg and Scarpa [21], Kosenius [44], and Hynes et al. [49], who find that willingness to pay for marine quality is positively associated with recreational contact and supports the findings of numerous studies in the literature showing that underwater recreationists have strong preferences and willingness to pay for healthy reefs and diverse fish populations [21-23]. Importantly, poor water quality is expected to have a greater impact on snorkelers than on swimmers, as water quality affects health and has an impact on the visual aesthetic of the marine environment.

Limitations of this research include the possibility for biased responses due to the hypothetical nature of our environmental change scenarios and the difficulties associated with separating environmental reasons for changes in aggregate visitation from other factors that affect demand. Future research could attempt to follow-up with respondents regarding actual revisit behaviors to empirically validate stated intentions. Combining information on the time trend of coastal and marine quality with estimates of return visitation over time could serve to isolate the overall impact of environmental change.

\section{Conclusions}

Repeat visitation signals satisfaction with a destination's attributes and is an important component in maintaining predictable tourist benefits and economic stability. With a return visitation rate near 50 percent, repeat visitors are critically important to the tourism-based economy of Barbados. Our examination of tourists' stated intentions to return to Barbados under scenarios of environmental change suggests that return tourism demand is highly vulnerable to continued losses in coastal and 
marine quality. Our results confirm the results of monetary valuation studies that suggest WTP by visitors to "sun, sea and sand" destinations is highly sensitive to coastal and marine degradation. Results presented here complement the existing WTP literature by providing non-monetary estimates of the potential consequences of continued nearshore degradation.

Of interest is the fact that seawater quality, a key driver of the health of coral reef ecosystems (i.e., coral and associated marine life) and indirectly related to beach width (as the producer of sand), was the attribute that visitors cared most about. These findings help to clarify policy focus regarding management actions designed to prevent coastal and marine degradation. In terms of maximizing returns from tourism, it seems clear that the focus of policy should be on preventing further declines in seawater quality.

These results are timely for Barbados. First, recent reductions in seawater quality and associated health hazards from sewage issues have resulted in negative media coverage. Governments from Barbados' main source markets (U.K., U.S. and Canada) issued travel warnings against visiting Barbados due to health concerns associated with this pollution, pointing to the need to understand the potential effect on the economy. Our results suggest that if the sewage issues are not resolved, the impact on the Barbadian economy via return tourism could be quite significant. Results from WTP studies in Barbados and elsewhere in the Caribbean suggest that recovering the costs associated with improving nearshore water quality may be feasible through pricing mechanisms such as conservation fees or higher prices for lodging and recreation, but our results imply that there may not be economic gains created through increased visitation.

Our results also support the Barbados Government's new strategic direction to develop a strong blue economy as seen in the 2018 creation of a 'Ministry of Maritime Affairs and Blue Economy' and the recent commitments of the Barbados Government at the Sustainable Blue Economy Conference in Kenya, November 2018. At this global gathering, the Government of Barbados announced the intention to follow a 'Roof to reefs' model (requiring management of land-based activities) in support of building its Blue Economy. Our results provide strong justification for this need to manage land-based activities to prevent further deterioration of coastal water. Efforts to restore reef ecosystems and mitigate coastal erosion are likely to result in lower returns if not coupled with management actions designed to prevent additional losses in seawater quality.

Beyond the importance for Barbados, this research highlights a relatively unexplored avenue for understanding the tradeoffs between environmental quality and the economic returns from tourism. The examination of how changes in environmental quality might affect people's behavior can provide insights that complement and extend the information gleaned from willingness to pay studies. First, understanding behavioral changes such as tourists' willingness to return to a destination can help bring the importance of natural resources and ecosystem services into the policy arena by highlighting the impact on tourism demand-a tangible and easily understood metric in locations where tourism is the principle economic driver. Furthermore, asking people to respond to behavioral questions avoids the difficulty of respondents having no prior experience with the monetary transactions proposed in WTP questions, which may lead to the expression of unreliable "constructive preferences" [53]. Estimates of behavioral change also avoid the moral, ethical and reductionist concerns associated with "commodifying" nature in monetary terms [54] and may minimize hypothetical bias in the case of familiar private goods such as travel [55]. Finally, willingness to return may be a more sensible expression of value than willingness to pay in the context of tourism. If visitors are not presented with a genuine opportunity to contribute monetary resources to conservation initiatives at a destination, they may simply "vote with their feet" and travel elsewhere.

Despite these advantages, contingent behavior studies examining the sensitivity of tourism demand to environmental quality are scarce in the literature. Given the relative ease of designing and analyzing willingness to return questions, valuation practitioners and tourist destinations that are dependent on natural resource quality would be advised to consider complementing existing 
assessments with hypothetical scenarios involving potential environmental change such as those used in this work.

Author Contributions: Conceptualization, P.S., R.S., R.W. and H.A.O.; Methodology, P.S., R.S., P.B.-S., and D.A.G.; Data Curation, P.S., R.S. and R.W.; Writing-Original Draft Preparation, P.S., R.S., R.W., P.B.-S., J.C., H.A.O. and D.A.G.; Writing-Review \& Editing, P.S., R.S., P.B.-S., J.C., H.A.O. and D.A.G.; Supervision, P.S. and R.S.; Project Administration, P.S., R.S. and R.W.; Funding Acquisition, P.S., R.S. and R.W.

Funding: The APC was funded by the Cameron School of Business at the University of North Carolina Wilmington.

Acknowledgments: Support for this study was provided by the Caribbean Tourism Organization, the World Resources Institute and the Cameron School of Business at the University of North Carolina Wilmington. Additional support was provided by the Centre for Resource Management and Environmental Studies at the University of the West Indies-Cave Hill. Valuable consultation was provided by the Barbados Coastal Zone Management Unit and the Inter-American Development Bank. Mary J. Densmore and Jason A. Walsh provided significant administrative support.

Conflicts of Interest: The authors declare no conflict of interest.

\section{References}

1. Dharmaratne, G.S.; Brathwaite, A.E. Economic valuation of the coastline for tourism in Barbados. J. Travel Res. 1998, 37, 138-144. [CrossRef]

2. Burke, L.; Maidens, J. Reefs at Risk in the Caribbean; World Resources Institute: Washington, DC, USA, 2004; p. 80 .

3. Bryant, R.L. Power, knowledge and political ecology in the third world: A review. Prog. Geogr. 1998, 22, 79-94. [CrossRef]

4. Burke, L.; Reytar, K.; Spalding, M.; Perry, A. Reefs at Risk Revisited; World Resources Institute: Washington, DC, USA, 2011; p. 144.

5. UNDESA. World Urbanization Prospects; the 2011 Revision; Population Division, Department of Economic and Social Affairs, United Nations Secretariat: New York, NY, USA, 2014.

6. Myсоо, M. Sustainable tourism using regulations, market mechanisms and green certification: A case study of Barbados. J. Sustain. Tour. 2006, 14, 489-511. [CrossRef]

7. Bell, P. Review paper: Eutrophication and coral reefs-some examples in the Great Barrier Reef lagoon. Water Resour. 1992, 26, 553-568. [CrossRef]

8. Hunte, W.; Wittenberg, M. Effects of eutrophication and sedimentation on juvenile corals. Mar. Biol. 1992, 114, 625-631. [CrossRef]

9. World Health Organization. Guidelines for Safe Recreational Water Environments: Coastal and Fresh Waters; World Health Organization: Geneva, Switzerland, 2003.

10. Pond, K. Water Recreation and Disease: Plausibility of Associated Infections: Acute Effects, Sequelae, and Mortality; World Health Organization: Geneva, Switzerland, 2005.

11. Loomis, J.B. An investigation into the reliability of intended visitation behavior. Environ. Resour. Econ. 1993, 3, 183-191. [CrossRef]

12. Mittal, V.; Kamakura, W.A. Satisfaction, repurchase intent, and repurchase behavior: Investigating the moderating effect of customer characteristics. J. Mark. Res. 2001, 38, 131-142. [CrossRef]

13. Grijalva, T.C.; Berrens, R.P.; Bohara, A.K.; Shaw, W.D. Testing the validity of contingent behavior trip responses. Am. J. Agric. Econ. 2002, 84, 401-414. [CrossRef]

14. Halkos, G.; Matsiori, S. Environmental attitudes and preferences for coastal zone improvements. Econ. Anal. Pol. 2018, 58, 153-166. [CrossRef]

15. García-Ayllón, S. New Strategies to Improve Co-Management in Enclosed Coastal Seas and Wetlands Subjected to Complex Environments: Socio-Economic Analysis Applied to an International Recovery Success Case Study after an Environmental Crisis. Sustainability 2019, 11, 1039. [CrossRef]

16. Casey, J.F.; Schuhmann, P.W. PACT or no PACT are tourists willing to contribute to the Protected Areas Conservation Trust in order to enhance marine resource conservation in Belize? Mar. Policy 2019, 101, 8-14. [CrossRef] 
17. Schuhmann, P.W.; Skeete, R.; Waite, R.; Lorde, T.; Bangwayo-Skeete, P.; Oxenford, H.A.; David, G.; Moore, W.; Spencer, F. Visitors' willingness to pay marine conservation fees in Barbados. Tour. Manag. 2019, 71, 315-326. [CrossRef]

18. Trujillo, J.C.; Carrillo, B.; Charris, C.A.; Velilla, R.A. Coral reefs under threat in a Caribbean marine protected area: Assessing divers' willingness to pay toward conservation. Mar. Policy 2016, 68, 146-154. [CrossRef]

19. Pakalniete, K.; Aigars, J.; Czajkowski, M.; Strake, S.; Zawojska, E.; Hanley, N. Understanding the distribution of economic benefits from improving coastal and marine ecosystems. Sci. Total Environ. 2017, 584, $29-40$. [CrossRef] [PubMed]

20. Christie, M.; Remoundou, K.; Siwicka, E.; Wainwright, W. Valuing marine and coastal ecosystem service benefits: Case study of St Vincent and the Grenadines' proposed marine protected areas. Ecosyst. Serv. 2015, 11, 115-127. [CrossRef]

21. Beharry-Borg, N.; Scarpa, R. Valuing quality changes in Caribbean coastal waters for heterogeneous beach visitors. Ecol. Econ. 2010, 69, 1124-1139. [CrossRef]

22. Gill, D.A.; Schuhmann, P.W.; Oxenford, H.A. Recreational diver preferences for reef fish attributes: Economic implications of future change. Ecol. Econ. 2015, 111, 48-57. [CrossRef]

23. Cazabon-Mannette, M.; Schuhmann, P.W.; Hailey, A.; Horrocks, J. Estimates of the non-market value of sea turtles in Tobago using stated preference techniques. J. Environ. Manag. 2017, 192, 281-291. [CrossRef]

24. Sorice, M.G.; Oh, C.-O.; Ditton, R.B. Managing Scuba Divers to Meet Ecological Goals for Coral Reef Conservation. AMBIO 2007, 36, 316-322. [CrossRef]

25. Rodrigues, L.C.; van den Bergh, J.C.; Loureiro, M.L.; Nunes, P.A.; Rossi, S. The Cost of Mediterranean Sea Warming and Acidification: A Choice Experiment among Scuba Divers at Medes Islands, Spain. Environ. Res. Econ. 2015, 63, 289-311. [CrossRef]

26. Shideler, G.S.; Pierce, B. Recreational diver willingness to pay for goliath grouper encounters during the months of their spawning aggregation off eastern Florida, USA. Ocean Coast. Manag. 2016, 129, 36-43. [CrossRef]

27. Alegre, J.; Cladera, M. Repeat visitation in mature sun and sand holiday destinations. J. Travel Res. 2006, 44, 288-297. [CrossRef]

28. World Travel and Tourism Council. Travel and Tourism Economic Impact 2018; World Travel and Tourism Council: London, UK, 2018.

29. BSS. Barbados Statistical Services Annual Report. Available online: https://www.barstats.gov.bb/ (accessed on 19 February 2019).

30. BTMI. Annual Statistical Report, 2017th ed.; Research Department, Barbados Tourism Marketing Inc.: Michael, Barbados, 2017.

31. Lewis, J.B. Evidence from aerial photography of structural loss of coral reefs at Barbados, West Indies. Coral Reefs 2002, 21, 49-56. [CrossRef]

32. Jackson, J.B.C.; Donovan, M.K.; Cramer, K.L.; Lam, V.V. (Eds.) Status and Trends of Caribbean Coral Reefs: 1970-2012; Global Coral Reef Monitoring Network, IUCN: Gland, Switzerland, 2014; p. 304.

33. Office of Research. The Barbados Coral Reef Monitoring Programme: Changes in Coral Reef Communities on the West and South Coasts 2002-2012; University of the West Indies: Wanstead, Barbados, 2014; p. 92.

34. Tomascik, T.; Sander, F. Effects of eutrophication on reef-building corals. I. Growth rate of the reef-building coral. Mar. Biol. 1985, 87, 143-155. [CrossRef]

35. Tomascik, T.; Sander, F. Effects of eutrophication on reef-building corals. II. Structure of scleractinian coral communities on fringing reefs, Barbados, West Indies. Mar. Biol. 1987, 94, 53-75. [CrossRef]

36. Tomascik, T.; Sander, F. Effects of eutrophication on reef-building corals. III. Reproduction of the reef-building coral. Mar. Biol. 1987, 94, 77-94. [CrossRef]

37. Snelgrove, P.V.R.; Lewis, J.B. Response of a coral-associated crustacean community to eutrophication. Mar. Biol. 1989, 101, 249-257. [CrossRef]

38. Marubinni, F.; Davies, P.S. Nitrate increases zooxanthellae population density and reduces skeletogenesis in corals. Mar. Biol. 1996, 127, 319-328. [CrossRef]

39. Holmes, K. Effects of eutrophication on bioeroding sponge communities with the description of new West Indian sponges, Cliona spp. (Porifera: Hadromerida: Clionidae). Invertebr. Biol. 2000, 119, 125-138. [CrossRef] 
40. DeGeorges, A.; Goreau, T.J.; Reilly, B. Land-sourced pollution with an emphasis on domestic sewage: Lessons from the Caribbean and implications for coastal development on Indian Ocean and Pacific coral reefs. Sustainability 2010, 2, 2919-2949. [CrossRef]

41. SEDU. The Sustainable Economic Development Unit (2002). Environmental Management Insertion in Tourism Sector Policies in the Caribbean; Final Report; Department of Economics, University of the West Indies, St. Augustine Campus: St. Augustine, Trinidad and Tobago.

42. Hanley, N.; Bell, D.; Alvarez-Farizo, B. Valuing the benefits of coastal water quality improvements using contingent and real behaviour. Environ. Res. Econ. 2003, 24, 273-285. [CrossRef]

43. Schuhmann, P.W.; Bass, B.E.; Casey, J.F.; Gill, D.A. Visitor preferences and willingness to pay for coastal attributes in Barbados. Ocean Coast. Manag. 2016, 134, 240-250. [CrossRef]

44. Kosenius, A.K. Heterogeneous preferences for water quality attributes: The case of eutrophication in the Gulf of Finland, the Baltic Sea. Ecol. Econ. 2010, 69, 528-538. [CrossRef]

45. MacDonald, D.H.; Ardeshiri, A.; Rose, J.M.; Russell, B.D.; Connell, S.D. Valuing coastal water quality: Adelaide, South Australia metropolitan area. Mar. Policy 2015, 52, 116-124. [CrossRef]

46. Eggert, H.; Olsson, B. Valuing multi-attribute marine water quality. Mar. Policy 2009, 33, 201-206. [CrossRef]

47. Tait, P.; Baskaran, R.; Cullen, R.; Bicknell, K. Nonmarket valuation of water quality: Addressing spatially heterogeneous preferences using GIS and a random parameter logit model. Ecol. Econ. 2012, 75, 15-21. [CrossRef]

48. Can, Ö.; Alp, E. Valuation of environmental improvements in a specially protected marine area: A choice experiment approach in Göcek Bay, Turkey. Sci. Total Environ. 2012, 439, 291-298. [CrossRef] [PubMed]

49. Hynes, S.; Tinch, D.; Hanley, N. Valuing improvements to coastal waters using choice experiments: An application to revisions of the EU Bathing Waters Directive. Mar. Policy 2013, 40, 137-144. [CrossRef]

50. Um, S.; Chon, K.; Ro, Y. Antecedents of revisit intention. Ann. Tour. Res. 2006, 33, 1141-1158. [CrossRef]

51. Matute-Vallejo, J.; Bravo, R.; Pina, J.M. The influence of corporate social responsibility and price fairness on customer behaviour: Evidence from the financial sector. Corp. Soc. Resp. Environ. Manag. 2011, 18, 317-331. [CrossRef]

52. Baker, D.A.; Crompton, J.L. Quality, satisfaction and behavioral intentions. Ann. Tour. Res. 2000, $27,785-804$. [CrossRef]

53. Ajzen, I.; Brown, T.C.; Rosenthal, L.H. Information bias in contingent valuation: Effects of personal relevance, quality of information, and motivational orientation. J. Environ. Econ. Manag. 1996, 30, 43-57. [CrossRef]

54. Neuteleers, S.; Engelen, B. Talking money: How market-based valuation can undermine environmental protection. Ecol. Econ. 2015, 117, 253-260. [CrossRef]

55. Whitehead, J.C. Environmental risk and averting behavior: Predictive validity of jointly estimated revealed and stated behavior data. Environ. Res. Econ. 2005, 32, 301-316. [CrossRef]

(C) 2019 by the authors. Licensee MDPI, Basel, Switzerland. This article is an open access article distributed under the terms and conditions of the Creative Commons Attribution (CC BY) license (http://creativecommons.org/licenses/by/4.0/). 